\title{
Mechanical Performances of Typical Robot Feet Intruding into Sands
}

\author{
Dianlei Han ${ }^{1}$, Rui Zhang ${ }^{1} * \mathbb{C}$, Hua Zhang ${ }^{2}$, Zhenyu $\mathrm{Hu}^{2}$ and Jianqiao $\mathrm{Li}^{1}$ \\ 1 Key Laboratory of Bionic Engineering, Ministry of Education, Jilin University, Changchun 130022, China; \\ hand115@mails.jlu.edu.cn (D.H.); jqli@jlu.edu.cn (J.L.) \\ 2 Aerospace Systems Engineering Shanghai, Shanghai 201109, China; Ases_zhang@163.com (H.Z.); \\ hzy_021@163.com (Z.H.) \\ * Correspondence: zhangrui@jlu.edu.cn
}

Received: 5 March 2020; Accepted: 7 April 2020; Published: 11 April 2020

\begin{abstract}
Four kinds of feet with typical structures, referred to as the hemispherical foot, the semicylindrical foot, the rectangular foot and the circular foot, respectively, were designed and manufactured to study the foot-terrain interaction mechanics for legged robots. Three kinds of quartz sand were selected to study how particle size, shape and compactness affected the physical properties of the substrate and the intrusion performance of mechanical feet. The media with smaller particle sizes had higher bulk densities and lower angles of stability, but no obvious rule was found for particle shapes of quartz sand with different sizes. The intrusion resistive forces and pressures of the hemispherical foot on these three kinds of quartz sand were all less compared with the other three mechanical feet. The particle disturbance areas and motion trends were compared under these four kinds of mechanical feet using discrete element method simulations. The intrusion resistive forces of these mechanical feet first increased and then decreased with the increasing particle sizes of the quartz sand. Moreover, the intrusion resistive forces of these mechanical feet on spherical particles were smaller compared with irregular particles. The corresponding resistive forces of the mechanical feet were characterized based on the compactness of the quartz sand. According to the intrusion test data, the classic pressure-sinkage model was modified, and the relationships between intrusion resistive force and mechanical foot depth were obtained.
\end{abstract}

Keywords: robot feet with typical structures; intrusion resistive force; mechanical performances; quartz sand; discrete element method

\section{Introduction}

Particle-composed granular media (e.g., silt, sand, gravel and mud) are very ubiquitous in nature and are the main sources of substrate changes. They spread everywhere with exposed soil for animals to cross, including coastal habitats, deserts and savannas [1,2]. Granular media behave like either solids or fluids depending on the magnitude of the yield stress they are subjected to [3]. When an external force exceeds the yield stress, granular media begin to flow and act like fluids [1], but when the external force is less than the yield stress, the particles will not flow and will instead behave like solids. Granular media can also be compressed to narrow the space between constituent particles, forming a jamming state. As a result, their densities, packings, volume fractions and the yield stress necessary for fluidization will increase $[4,5]$. This compression results in the jamming of constitutive particles, so the granular media also behave like solids [6,7]. Granular media are highly heterogeneous [8] due to the variations in size, shape, compactness, friction coefficient of particles and inner moisture [5]. All these characteristics impact the physical properties of granular media, such as loading ability, angle of stability and bulk density [9], some of which are quantifiable indoors or in the field. 
Compared with a wheeled or tracked mobile mechanism, the legged mobile mechanism features high trafficability, obstacle surmounting, anti-subsidence and wear resistance on soft ground, mainly because the contact points between a mechanical foot and the ground are discrete. Years of development have made legged robots increasingly critical in the field activities of humans. Mechanical feet, in direct contact with the ground, are the key component of a legged robot, and their structure and shape are two important factors influencing the trafficability of the legged robot on uneven ground [10]. Many robot feet are flat and have large contact areas on flat terrain. Most humanoid robots have flat and rectangular feet, such as ASIMO [11] and PETMAN [12]. For freer adaption to rugged terrain, a legged robot is often designed with cylindrical or spherical feet, such as BigDog [13], LS3 [14] and LittleDog [15], for walking or running on rugged terrain.

Legged mobile mechanisms have also been gradually adopted in the field of deep space exploration, such as DLR Crawler, a hexapod robot developed by the Institute of Robotics and Mechatronics, German Aerospace Center [16]; Ambler, a hexapod robot developed by Carnegie Mellon University [17]; Dante II, a robot developed by NASA [18]; and iStruct Demonstrator, a chimpanzee-like robot developed by the German Artificial Intelligence Research Center.

Many of the existing and future legged robots are, or will be, designed to cross either structured or flat hard field terrain. Contact mechanics are essential in the manufacture of legged robots [19]. With very detailed work, a resistive force theory was proposed to simulate motion on granular media $[2,5,20]$. The effects of granular medium properties on motion were systematically studied to alter the volume fraction in a single medium [21,22].

Terramechanics from traditional terrestrial vehicles are widely used to explore the interaction mechanics of wheeled mobile robots [23]. Other scholars have built fundamental terramechanics models [24-26]. The existing classic theory on pressure and depth does not include the area parameter, because the areas of test objects in classic mechanical models are considered to be regular. However, the areas of both hemispherical feet and semicylindrical feet gradually change with increasing intrusion depth.

Based on terramechanics, Ding et al. established a foot-terrain interaction mechanical model for legged robots through modeling and experimental validation [10]. This mechanical model can predict the normal and tangential forces using parameters directly related to soils and feet and can reveal the parameter identification methods.

Understanding the response of granular matter to the intrusion of solid objects is key to modeling many aspects of the behavior of granular matter, including plastic flow. To explain the curve's nonlinear part in terms of the stagnant zone's development, Kang et al. reported a general model for such a quasistatic process and further showed that the intrusion of any convex solid shape satisfied a modified Archimedes' law [27].

Yeomans and Saaj applied ideas from the developing study of granular materials together with a detailed characterization of the sinkage process to propose and validate a combined model of terrain interaction based on an understanding of physics and micro-mechanics at the granular level [28].

Unfortunately, the works above mostly considered only one or two arbitrary granular media and did not quantify their physical properties. In addition, more attention was paid to the parameters related to the foot-terrain interaction model, but not to the influence of other physical properties on the intrusion resistive force of mechanical feet, such as particle size, shape and compactness. The topic of this paper regards the class of imperfect systems [29]. For this reason, we explored the impacts of some physical properties of quartz sand on the intrusion ability of mechanical feet.

How would particle size, shape and compactness impact the physical properties of the substrate and the intruding ability of mechanical feet? We expected that smaller particles would possess higher bulk density owing to larger cohesive forces and tighter packing [30], which would enhance the resistive force of mechanical feet. However, in a previous study, the angle of stability decreased because of the lighter and less stable particles [5]. We also predicted that irregular versus spherical particles would generate larger resistive forces because the irregular shapes would contribute to packing and increasing 
inner friction [31,32]. To modify the classic pressure-depth model and introduce the influence of cross-sectional area change, we carried out some preliminary research and compared the intrusion abilities of mechanical feet. We predicted that irregular feet would outperform in intrusion mainly owing to their smaller cross-sectional areas for the same surface area.

\section{Materials and Methods}

\subsection{Design of Mechanical Feet}

Four kinds of mechanical feet (Figure 1), the hemispherical foot, the semicylindrical foot, the rectangular foot and the circular foot, respectively, were designed and manufactured based on the existing foot morphology of most bipedal robots. The thickness of each mechanical foot was $35 \mathrm{~mm}$, and the plantar surface area was $9815 \mathrm{~mm}^{2}$.

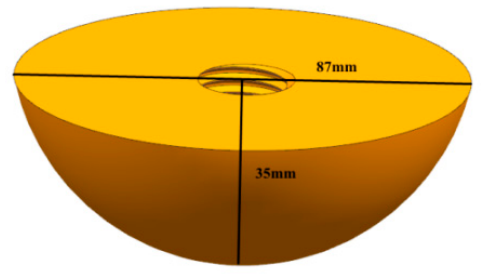

(a) Hemispherical foot

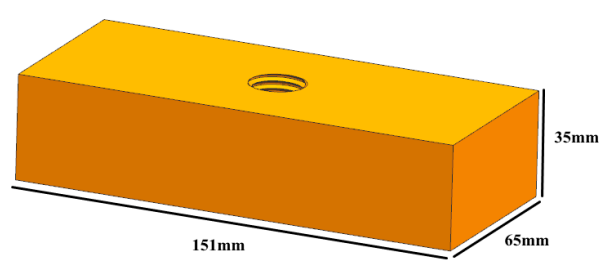

(c) Rectangular foot

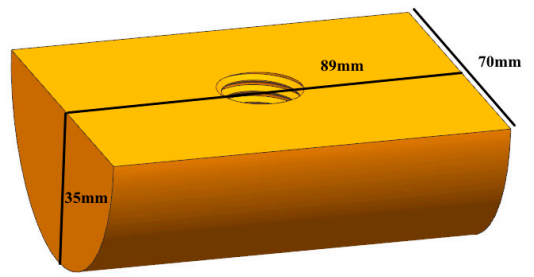

(b) Semicylindrical foot

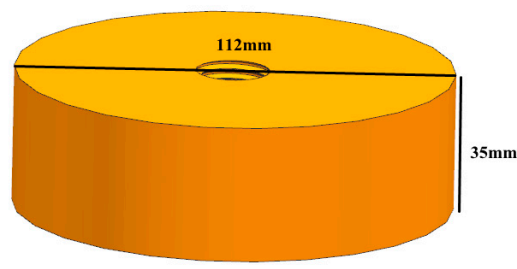

(d) Circular foot

Figure 1. Design of mechanical feet.

\subsection{Intrinsic Parameter Tests and Virtual Parameter Calibrations}

Three kinds of quartz sand with different particle sizes were selected as the test media. The particle size distributions and corresponding mass fractions of each medium are shown in Table 1. The intrinsic parameters of the three media were detected using a bulk density device, a stability angle device and a triaxial shear instrument (Model SLB-1, Nanjing soil instrument factory, China) (Table 2).

Table 1. Mass and proportion of quartz sand with different particle sizes.

\begin{tabular}{lcccccc}
\hline & & \multicolumn{5}{c}{ Particle Size Distributions (mm) } \\
\cline { 3 - 6 } & & $\mathbf{0 - 0 . 3}$ & $\mathbf{0 . 3 - 0 . 6 3}$ & $\mathbf{0 . 6 3 - 1 . 2 5}$ & $\mathbf{1 . 2 5 - 1 . 6}$ & $\mathbf{1 . 6 - 3}$ \\
\hline \multirow{2}{*}{ Quartz sand 1 } & Mass (g) & 16 & 68 & 408 & & \\
& Proportion (\%) & 3.3 & 13.8 & 82.9 & & \\
Quartz sand 2 & Mass (g) & & 14 & 324 & 160 & \\
& Proportion (\%) & & 2.8 & 65 & 32 & \\
Quartz sand 3 & Mass (g) & & & 124 & 216 & 156 \\
& Proportion (\%) & & & 25 & 43.5 & 31.5 \\
\hline
\end{tabular}


Table 2. The intrinsic parameters of three kinds of quartz sand.

\begin{tabular}{|c|c|c|c|c|c|c|c|}
\hline & \multirow[b]{2}{*}{$\begin{array}{l}\text { Bulk Density } \\
\left(\mathrm{Kg} \cdot \mathrm{m}^{-3}\right)\end{array}$} & \multicolumn{3}{|c|}{ Angle of Stability $\left(^{\circ}\right)$} & \multirow{2}{*}{$\begin{array}{l}\text { Elasticity } \\
\text { Modulus } \\
\text { (MPa) }\end{array}$} & \multirow[b]{2}{*}{$\begin{array}{l}\text { Poisson } \\
\text { Ratio }\end{array}$} & \multirow{2}{*}{$\begin{array}{l}\text { Shear } \\
\text { Modulus } \\
\text { (MPa) }\end{array}$} \\
\hline & & $\begin{array}{c}\text { Drawing } \\
\text { Plate Method }\end{array}$ & $\begin{array}{l}\text { Funnel } \\
\text { Method }\end{array}$ & Mean \pm S.D. & & & \\
\hline Quartz sand 1 & $1464.44 \pm 4.01$ & $30.93 \pm 0.45$ & $31.80 \pm 1.57$ & $31.37 \pm 1.14$ & 23.97 & 0.48 & 8.12 \\
\hline Quartz sand 2 & $1394.90 \pm 4.78$ & $31.47 \pm 1.01$ & $33.23 \pm 0.91$ & $32.35 \pm 1.29$ & 17.28 & 0.48 & 5.85 \\
\hline Quartz sand 3 & $1294.59 \pm 4.21$ & $33.27 \pm 0.40$ & $34.37 \pm 1.26$ & $33.82 \pm 1.03$ & 15.59 & 0.48 & 5.28 \\
\hline
\end{tabular}

The media with different particle sizes were successively placed in an image particle analyzer (Model BT-1600, Bettersize, China) to observe their shapes. The particle shapes of quartz sand 1 with the size of $0.63-1.25 \mathrm{~mm}$ are shown in Figure 2.

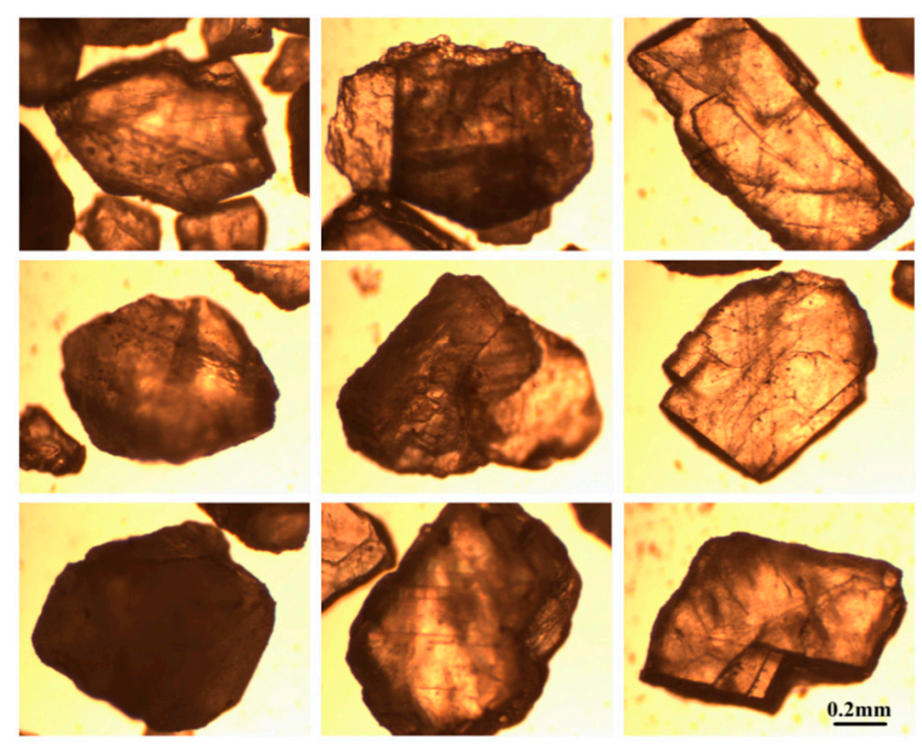

Figure 2. Typical particle shapes of quartz sand 1 with the size of $0.63-1.25 \mathrm{~mm}$.

The particles were divided by the characteristics of structure and contours into three typical shapes: sphere, strip and polygon. Each shape of particle with a different size was statistically analyzed (Figure 3). Clearly, polygonal particles account for a large proportion of the total under different particle sizes, which also indicates the irregularity of quartz sand shapes. 


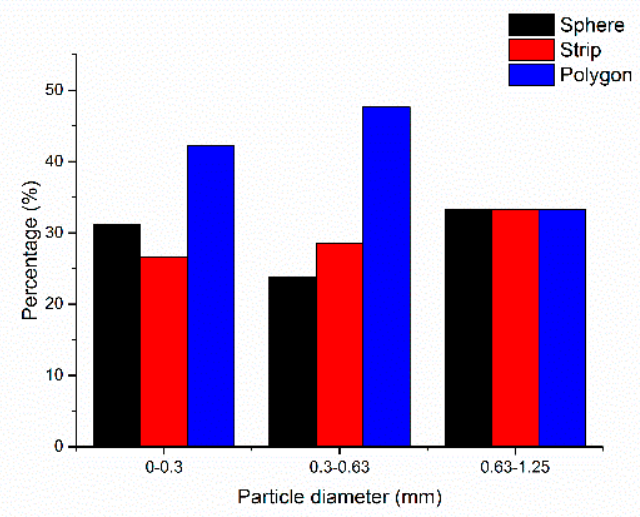

(a) Quartz sand 1

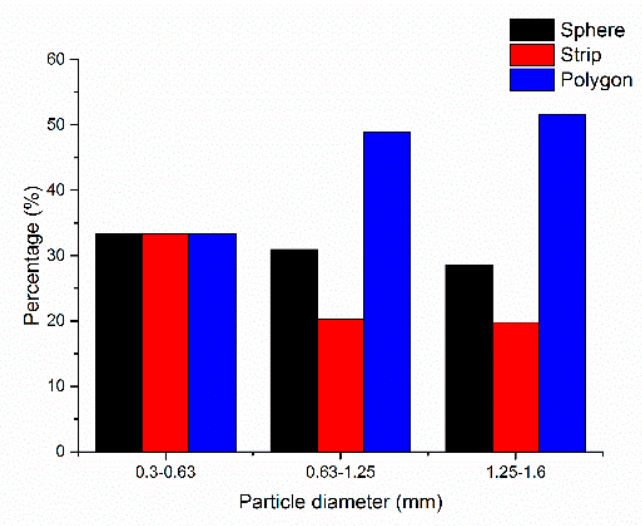

(b) Quartz sand 2

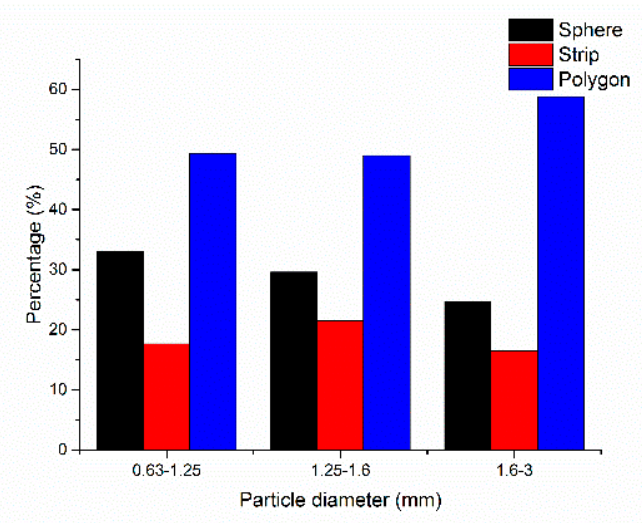

(c) Quartz sand 3

Figure 3. Statistical analysis of particle shapes.

\subsection{Mechanical Feet Intruding into Quartz Sand Tests}

The mechanical feet, the electronic universal testing machine (Model WDW, Airtimes, China), the data acquisition and control computer, and the sand preparation tools are shown in Figure 4. 


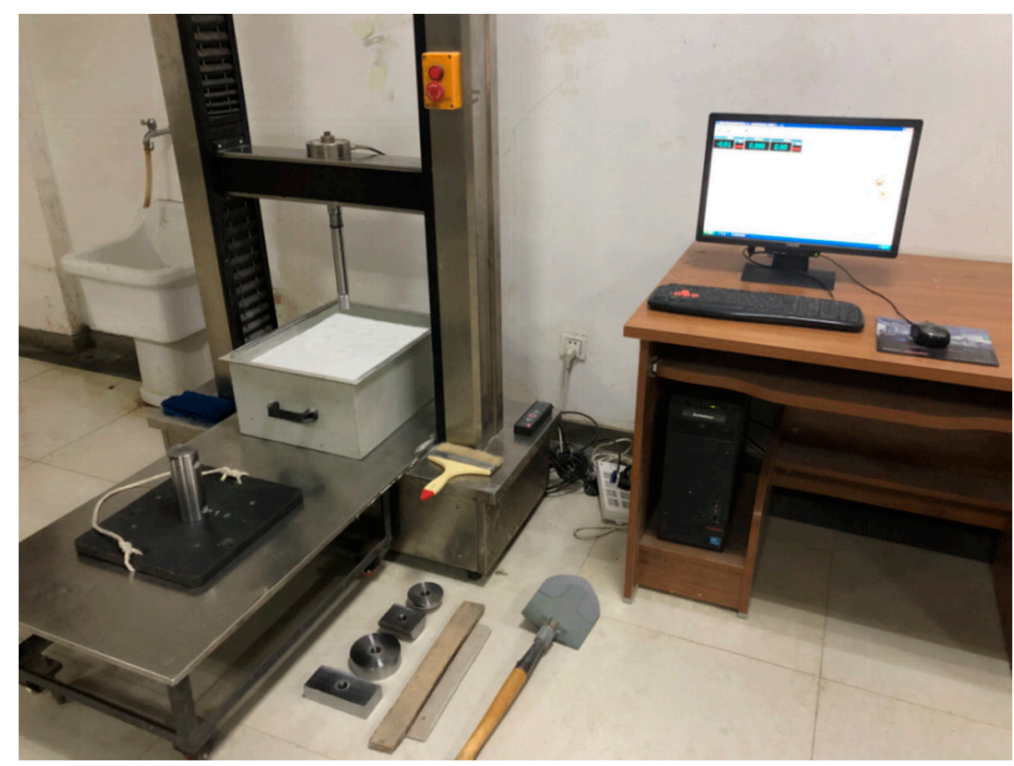

Figure 4. Intrusion test devices.

Before each test, a shovel was used to distribute the quartz sand evenly in the soil box, and then the sand surface was flattened with a scraper. The mechanical foot was installed in the electronic universal testing machine with adjustable speed, and its upward and downward motions were controlled by the computer. Data on the displacement and the intrusion resistive force were acquired and directly displayed on the computer when the foot uniformly intruded into the sand. Each condition was tested five times, and the average and standard deviation of the intrusion resistive force were calculated on Origin to provide the final result. Furthermore, the intrusion pressure of the foot was determined as the average resistive force divided by the instantaneous cross-sectional area of the foot during the intrusion process.

To verify the effect of intrusion velocity on the intrusion resistive force, we made the circular foot intrude into the loose quartz sand 1 at a uniform velocity of 40, 80, 120, 160 or $200 \mathrm{~mm} / \mathrm{min}$. The foot intrusion resistive forces from three repeated tests at each velocity were expressed as mean and standard deviation. No significant difference was found in the intrusion resistive force among the different velocities (Figure 5), indicating the intrusion velocity does not affect the intrusion resistive force. Thus, the intrusion velocity of $120 \mathrm{~mm} / \mathrm{min}$ was selected in the subsequent tests.

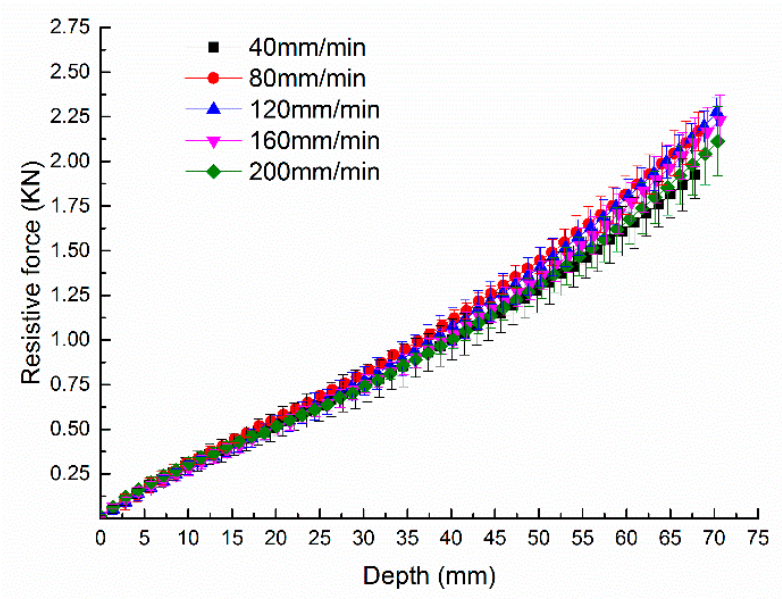

Figure 5. Influence of intrusion velocity on the intrusion resistive force. 
To study the impact of sand compactness on the foot intrusion resistive force, we laid a steel sheet on the sand surface after preparation and pressed down the steel sheet to make the loose sand compact using the universal testing machine. The intrusion pressure that indicated the degree of looseness or compactness of the sand was measured by a field scout soil compaction meter (SN: 991). Five linear points were selected for measurement, and the average and standard deviation were calculated.

\subsection{Discrete Element Simulation of Mechanical Feet Intruding into Quartz Sand}

The Hertz-Mindlin contact model is most commonly used to describe particle-particle interaction. The interaction parameters between particles and the rigid body were detected $[33,34]$. The coefficients of restitution, static friction and dynamic friction were $0.3,0.3$ and 0.2 , respectively. The density, Poisson ratio and shear modulus of the steel sheet were $7850 \mathrm{Kg} / \mathrm{m}^{3}, 0.3$ and $7 \times 10^{4} \mathrm{MPa}$, respectively. The inner interaction parameters between particles were calibrated using the angle of stability (Table 3 ).

Table 3. The interaction parameters between particles of three kinds of quartz sand.

\begin{tabular}{lccc}
\hline & $\begin{array}{c}\text { Coefficient of } \\
\text { Restitution }\end{array}$ & $\begin{array}{c}\text { Coefficient of Static } \\
\text { Friction }\end{array}$ & $\begin{array}{c}\text { Coefficient of Dynamic } \\
\text { Friction }\end{array}$ \\
\hline Quartz sand 1 & 0.55 & 0.32 & 0.05 \\
Quartz sand 2 & 0.15 & 0.2 & 0.2 \\
Quartz sand 3 & 0.35 & 1.16 & 0 \\
\hline
\end{tabular}

Based on the statistical analysis of particle shapes, three kinds of particles (sphere, strip and polygon) were identified. Among them, the strip and polygon particles were both assembled from regular spherical particles. The three typical particle shapes $0.63-1.25 \mathrm{~mm}$ in diameter in quartz sand 3 are shown in Figure 6. These three typical shapes were also used for other particles with different sizes in quartz sand 3 and the other two kinds of quartz sand. The size of the modeled particles was changed according to the actual particle size.

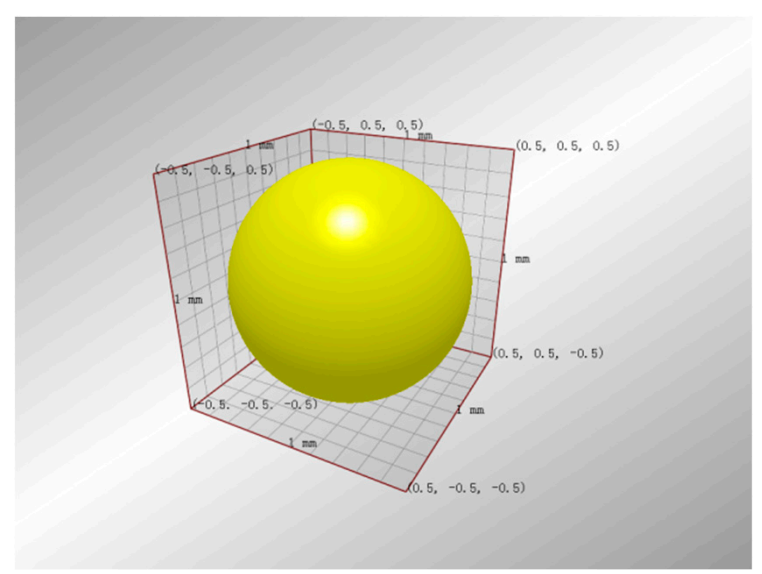

(a) Sphere

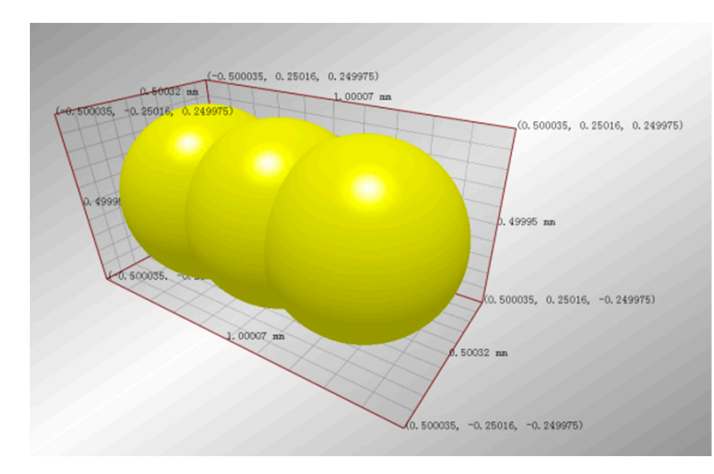

(b) Strip

Figure 6. Cont. 


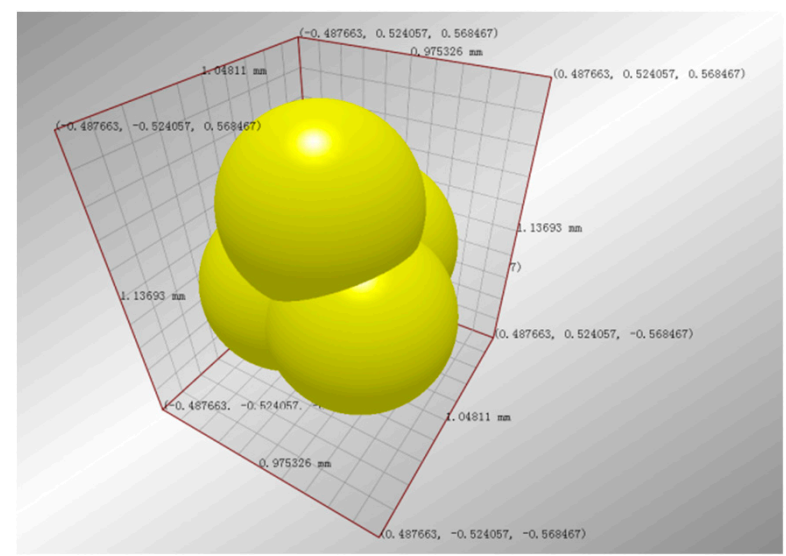

(c) Polygon

Figure 6. Three typical particle models $0.63-1.25 \mathrm{~mm}$ in size in quartz sand 3 .

During the entire intrusion process, the speed of the foot was set uniformly at the same intrusion speed as in the test $(120 \mathrm{~mm} / \mathrm{min})$, and the motion time was 5 seconds. Since the number of particles seriously affects the operational speed of the computer, we selected $1 / 4$ of the original size of each mechanical foot. In addition, this study focused on the dynamic mesoscopic mechanical behaviors of sand particles, such as the velocity fields, the contact force fields and the particle disturbance ranges. The size of the mechanical feet had little effect on the analyses of the simulation results [35].

Quartz sand 3 was selected to study the influence of particle shape on the foot intrusion resistive force. The particles were composed of irregular shapes, including spheres, strips and polygons, or only spherical shapes, and the intrusion resistive force of the same foot was compared.

\section{Results and Discussion}

\subsection{Comparisons of Intrusion Resistive Force and Pressure}

The intrusion resistive forces of the mechanical feet intruded into loose quartz sand 1, quartz sand 2 and quartz sand 3 are shown in Figure $7 \mathrm{a}-\mathrm{c}$, respectively. The intrusion resistive force of the hemispherical foot on loose quartz sand 1 was less than that of the other three mechanical feet. The intrusion resistive forces of the mechanical feet on loose quartz sand 2 and quartz sand 3 followed the same trend.

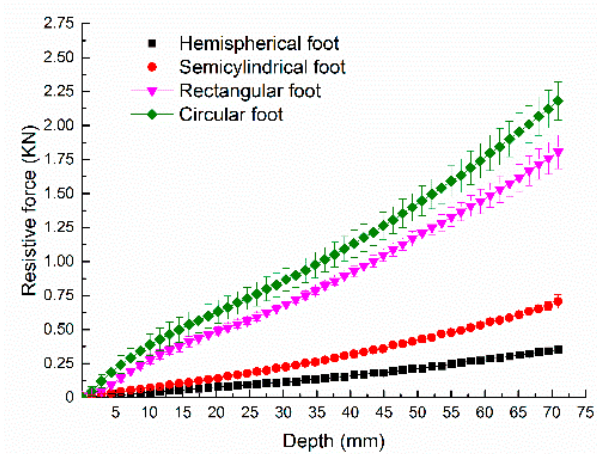

(a) Quartz sand 1

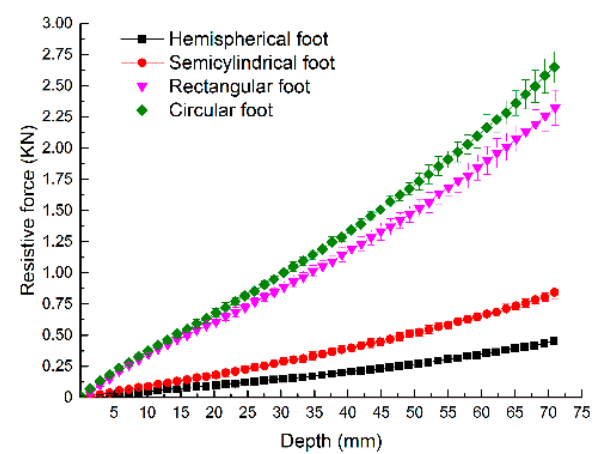

(b) Quartz sand 2

Figure 7. Cont. 


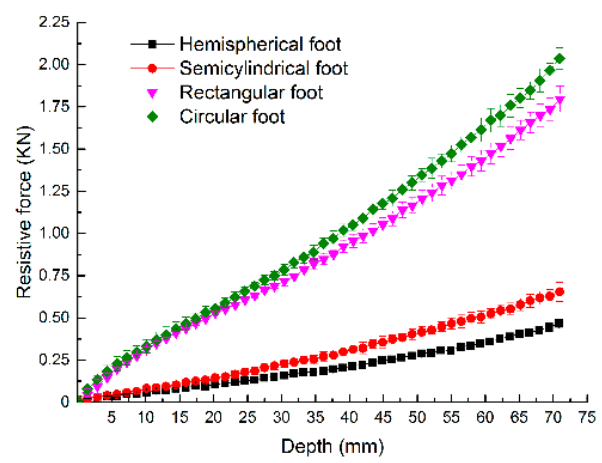

(c) Quartz sand 3

Figure 7. Comparisons of intrusion resistive forces for different feet.

The comparisons of intrusion pressures for different mechanical feet are shown in Figure 8. At the initial stage of intrusion, the pressures of the mechanical feet slightly increased, then decreased and steadily increased with the increasing depth, especially for the hemispherical foot on loose quartz sand 3. The reason for this phenomenon may be attributed to both the changes in foot intrusion cross-sectional area and the inertia characteristics of quartz sand. Then, at the stable stage of intrusion, the pressure of the hemispherical foot was less than that of the other three mechanical feet, regardless of the type of sand, which was the same for the resistive force.

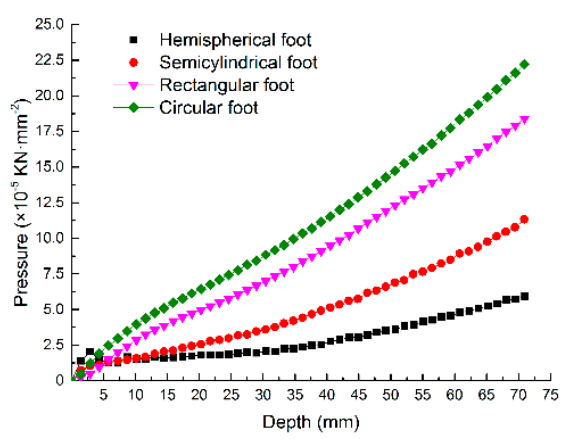

(a) Quartz sand 1

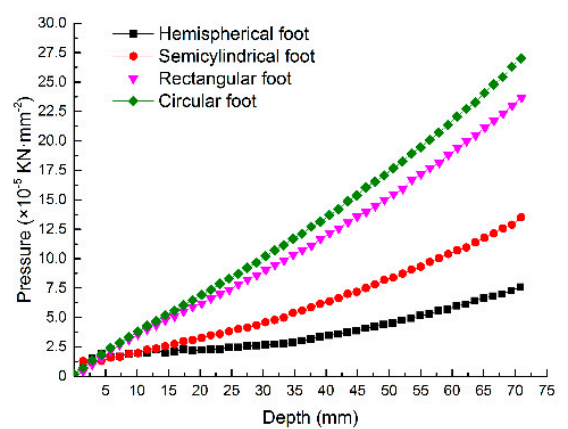

(b) Quartz sand 2

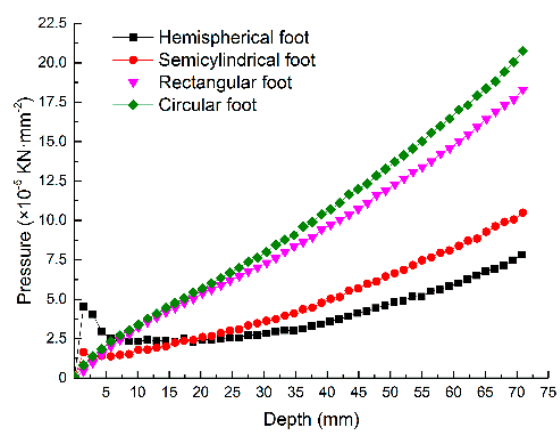

(c) Quartz sand 3

Figure 8. Comparisons of pressures for different feet. 


\subsection{Effect of Particle Size on Intrusion Resistive Force}

The effect of particle size on the foot intrusion resistive force is shown in Figure 9. For the semicylindrical foot, rectangular foot and circular foot, the intrusion resistive force on quartz sand 2 was the largest, while the forces on quartz sand 1 and quartz sand 3 were basically the same.

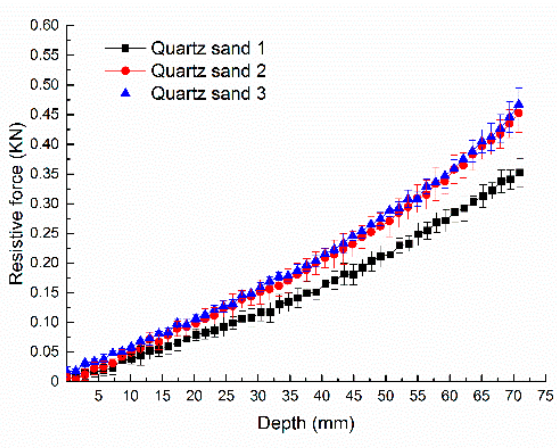

(a) Hemispherical foot

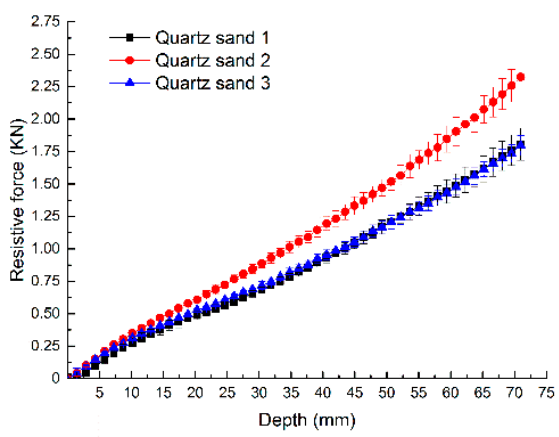

(c) Rectangular foot

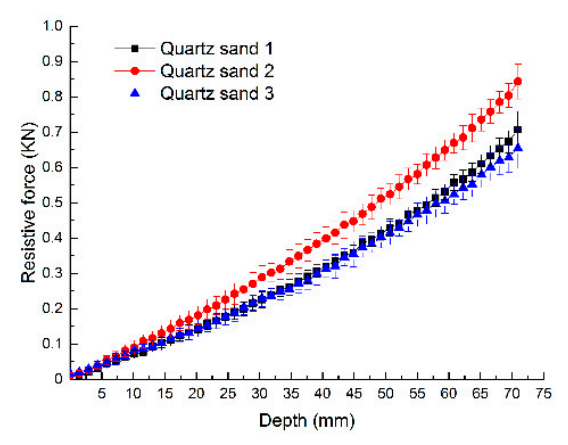

(b) Semicylindrical foot

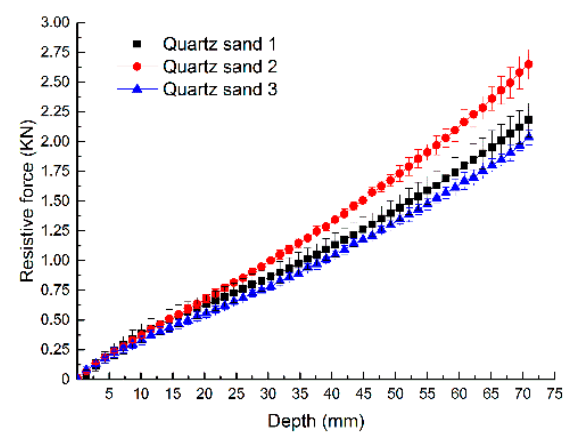

(d) Circular foot

Figure 9. Influence of particle size on the foot intrusion resistive force.

For media such as sand and gravel, particle shapes become more diverse and irregular as particle size increases, and the inner spaces also gradually increase, leading to a loose state of particles and a smaller intrusion resistive force. However, the intrusion resistive force first increased and then decreased with the increasing particle size, which was contrary to our initial hypothesis. We speculated that a particle size boundary with the largest intrusion resistive force existed in the granular substrates. To reveal the particle size boundary, we need more sand samples with different sizes. Moreover, the curve fitting method will be used to find the particle size corresponding to the maximum intrusion resistive force.

\subsection{Effect of Compactness on Intrusion Resistive Force}

The looseness and compactness degrees of quartz sand were characterized (Figure 10). Obviously, the cone index (intrusion pressure) of the compacted quartz sand was larger than that of the loose quartz sand. 


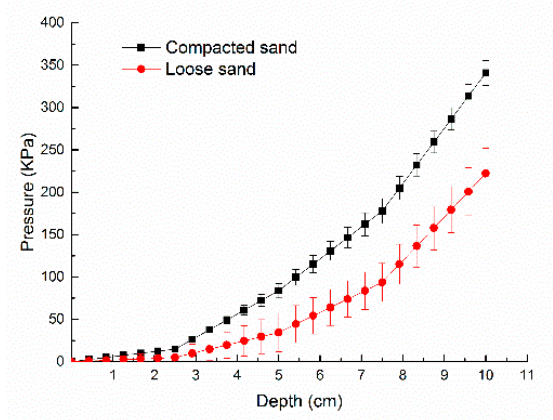

(a) Quartz sand 1

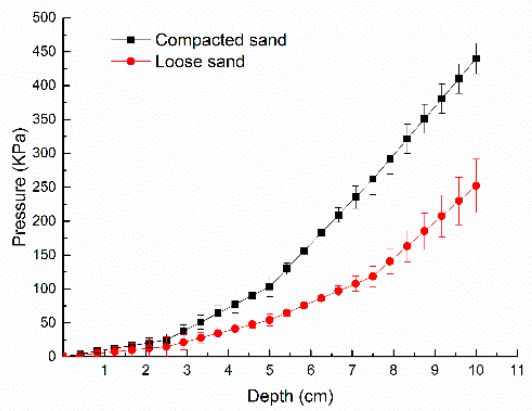

(b) Quartz sand 2

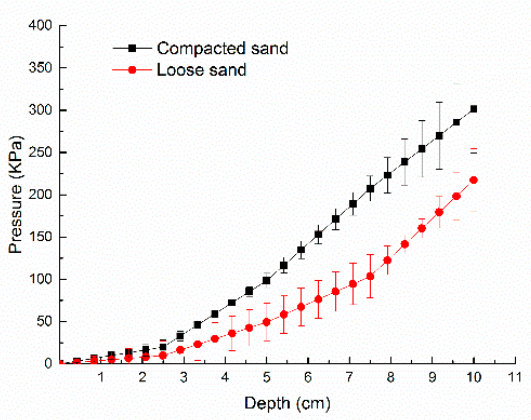

(c) Quartz sand 3

Figure 10. Cone indexes of three kinds of quartz sand.

The intrusion resistive forces of the mechanical feet into the compacted or loose quartz sand are shown in Figure 11. As the intrusion depth increased, the difference in the resistive forces the mechanical feet experienced between the compacted and loose quartz sand increased.

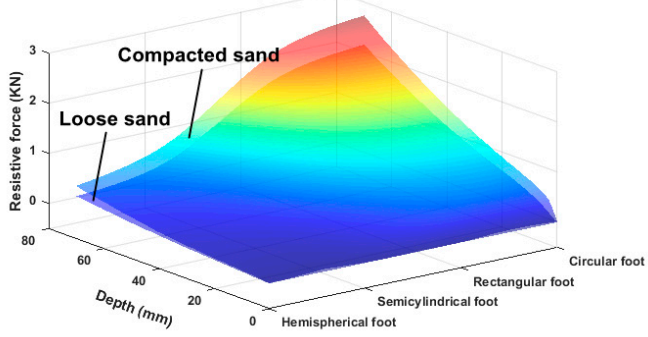

(a) Quartz sand 1

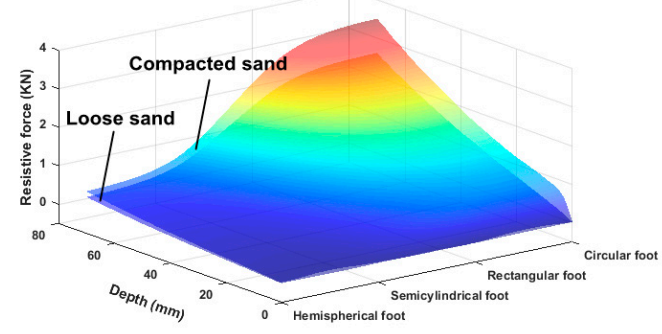

(b) Quartz sand 2

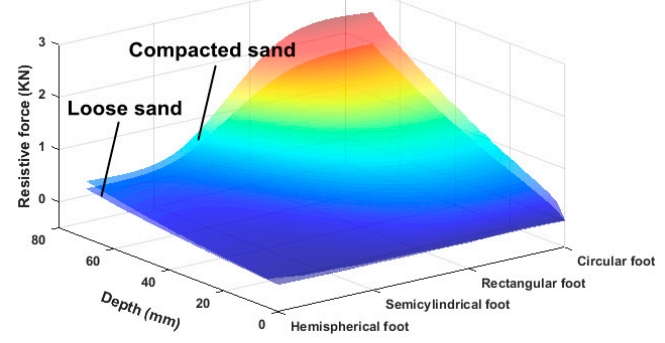

(c) Quartz sand 3

Figure 11. Effect of sand compact degree on the intrusion resistive force. 


\subsection{Simulation Results of Mechanical Foot Intruding into Quartz Sand}

\subsubsection{Velocity Field Comparison}

The variations in the particle velocity field as the mechanical feet intruded into quartz sand 3 are shown in Figure 12. As the mechanical foot further intruded into the quartz sand, the disturbed area of quartz sand expanded in a conical shape. The hardening cone grew further downward at the same velocity as the tested foot squeezed out the nearby particles [36]. The area, or volume, of the hardening cone slowly increased with the increasing intrusion depth. Hence, we estimated the reaction force for advancing motion was partly supplied by the solid properties of sand under the mechanical foot.

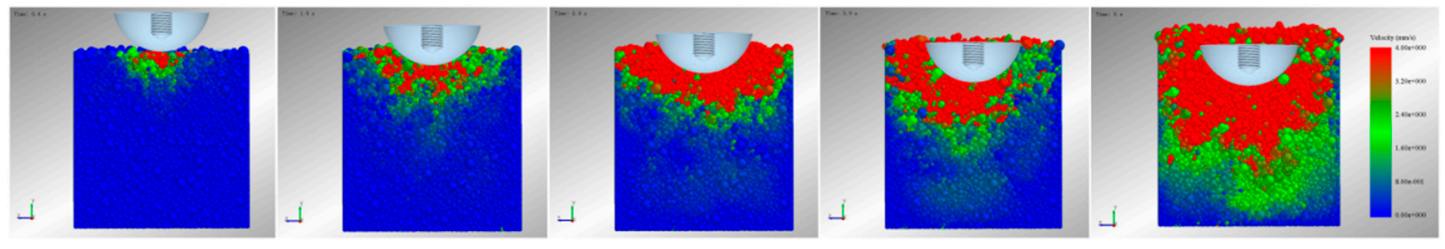

(a) Hemispherical foot

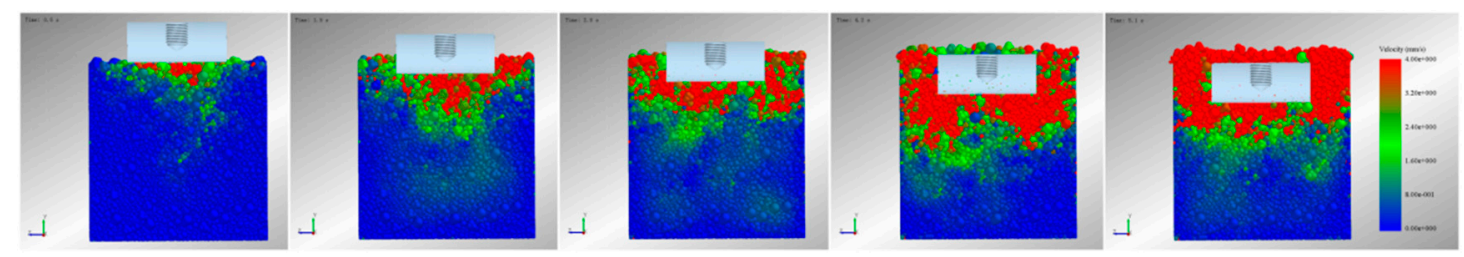

(b) Semicylindrical foot
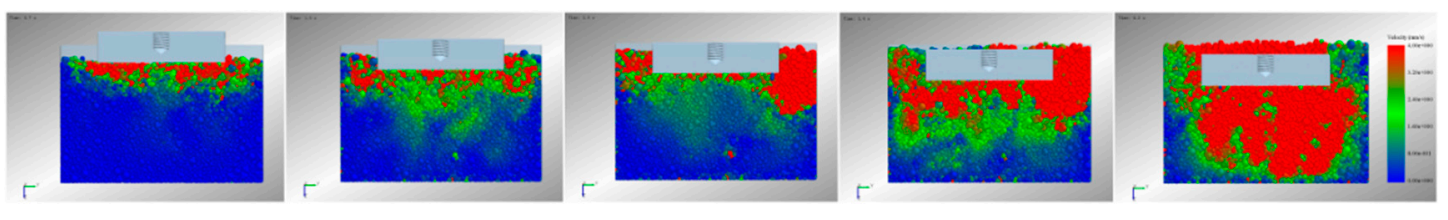

(c) Rectangular foot

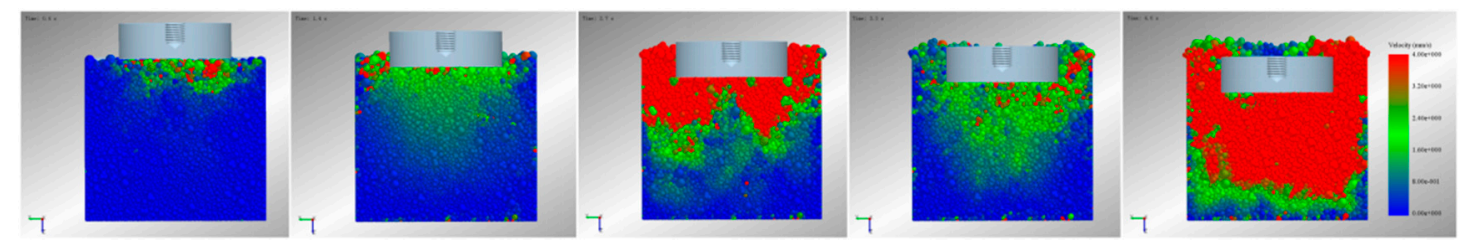

(d) Circular foot

Figure 12. The variations in particle velocity field during the intrusion of mechanical feet into quartz sand 3.

\subsubsection{Effect of Particle Shape on Intrusion Resistive Force}

The effect of particle shape on the foot intrusion resistive force is shown in Figure 13. The resistive force of intrusion into the irregular particles was greater compared with the regular spherical particles for all these four mechanical feet. This also confirms our hypothesis that irregular particles produce a greater intrusion resistive force against the mechanical feet than regular spherical particles. The main reason is that the shapes of irregular particles are more variable, which facilitates packing and increases inner friction. 


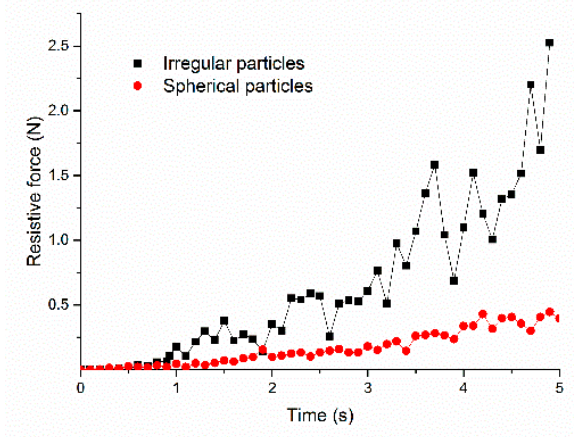

(a) Hemispherical foot

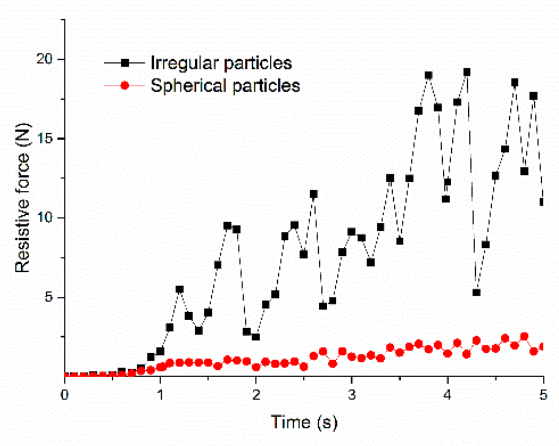

(c) Rectangular foot

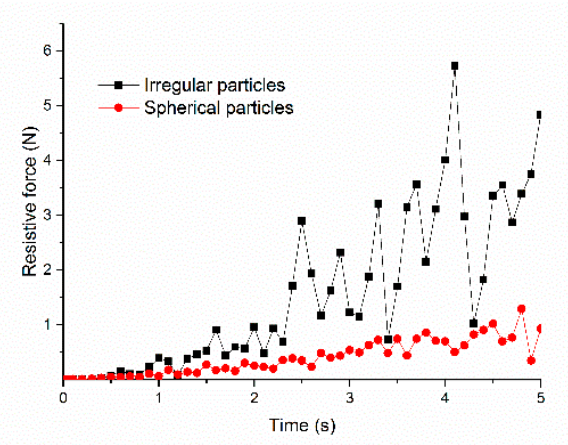

(b) Semicylindrical foot

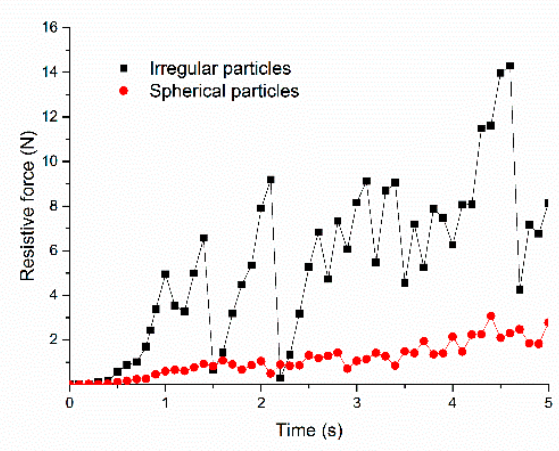

(d) Circular foot

Figure 13. The effect of particle shape on the foot intrusion resistive force.

\section{Mechanical Models of Robot Feet Intruding into Quartz Sand}

During soil deformation under vertical load, the sinkage is composed of an elastic region and a plastic region with a complex transition area. Since theoretical prediction of soil sinkage is difficult, plate sinkage experiments are usually performed to characterize the bearing performance of soil using semi-empirical equations. The classic Bernstein-Goriatchkin pressure-sinkage model [10] is shown as follows:

$$
P=K \times Z^{n}
$$

where $P$ is intrusion pressure, $\mathrm{MPa} ; K$ is intrusion coefficient, $\mathrm{MPa} \cdot \mathrm{m}^{-\mathrm{n}} ; \mathrm{Z}$ is intrusion depth, $\mathrm{m} ; n$ is intrusion depth index 1, dimensionless.

Based on Equation (1) and the test data of intrusion depth and resistive force, the intrusion model coefficients of different mechanical feet were determined (Table 4).

Table 4. Intrusion model coefficients.

\begin{tabular}{|c|c|c|c|c|c|c|}
\hline & \multicolumn{2}{|c|}{ Quartz Sand 1} & \multicolumn{2}{|c|}{ Quartz Sand 2} & \multicolumn{2}{|c|}{ Quartz Sand 3} \\
\hline & $K$ & $n$ & $K$ & $n$ & $K$ & $n$ \\
\hline Hemispherical foot & 0.10536 & 0.91888 & 0.13966 & 0.90701 & 0.36103 & 0.67265 \\
\hline$R^{2}$ & \multicolumn{2}{|c|}{0.85962} & \multicolumn{2}{|c|}{0.89583} & \multicolumn{2}{|c|}{0.58719} \\
\hline Semicylindrical foot & 0.06263 & 1.20465 & 0.09946 & 1.13823 & 0.08381 & 1.12071 \\
\hline$R^{2}$ & \multicolumn{2}{|c|}{0.98445} & \multicolumn{2}{|c|}{0.98547} & \multicolumn{2}{|c|}{0.97505} \\
\hline Rectangular foot & 0.18920 & 1.06698 & 0.23688 & 1.07143 & 0.26057 & 0.98692 \\
\hline $\mathrm{R}^{2}$ & \multicolumn{2}{|c|}{0.99601} & \multicolumn{2}{|c|}{0.99614} & \multicolumn{2}{|c|}{0.99464} \\
\hline Circular foot & 0.30313 & 0.99680 & 0.24921 & 1.09116 & 0.25219 & 1.02336 \\
\hline $\mathrm{R}^{2}$ & \multicolumn{2}{|c|}{0.99203} & \multicolumn{2}{|c|}{0.99652} & \multicolumn{2}{|c|}{0.99379} \\
\hline
\end{tabular}


For both the hemispherical foot and semicylindrical foot, the cross-sectional area gradually changed with increasing intrusion depth. Therefore, the power function (Equation (2)) was used to fit the relationship between the cross-sectional area of the mechanical foot $\left(A, \mathrm{~m}^{2}\right)$ and the intrusion depth (Table 5):

$$
A=a \times Z^{b}
$$

where $a$ is the coefficient of foot intrusion cross-sectional area, $\mathrm{m}^{2-\mathrm{b}} ; b$ is intrusion depth index 2 , dimensionless.

Table 5. The relationship between the cross-sectional area and the intrusion depth.

\begin{tabular}{cccc}
\hline & $a$ & & $b$ \\
\hline $\begin{array}{c}\text { Hemispherical foot } \\
(\mathrm{Z} \leq 0.035) \\
\mathrm{R}^{2}\end{array}$ & 0.1125 & & 0.8409 \\
$\begin{array}{c}\text { Semicylindrical foot } \\
(\mathrm{Z} \leq 0.035) \\
\mathrm{R}^{2}\end{array}$ & 0.0330 & 0.9921 & \\
\hline
\end{tabular}

On basis of the intrusion pressure, the classic intrusion resistance model was revised according to the relationship between the intrusion cross-sectional area of the mechanical foot and the intrusion depth (Equation (3)):

$$
F=K \times Z^{n} \times A
$$

where $F$ is the intrusion resistive force, $\mathrm{N}$.

The revised and integrated equations are shown in Table 6.

Table 6. Revised intrusion resistive force model.

\begin{tabular}{cc}
\hline & Intrusion Resistive Force Model \\
\hline Foot with variable cross-sectional area & $F=K^{\prime} \times Z^{n+b}$ where $K^{\prime}=a \times K(\mathrm{Z} \leq 0.035)$ \\
Foot with constant cross-sectional area & $F=K^{\prime \prime} \times Z^{n}$ where $K^{\prime \prime}=K \times A(\mathrm{Z}>0.035)$ \\
\hline
\end{tabular}

Note: $K^{\prime}\left(\mathrm{MPa} \cdot \mathrm{m}^{2-\mathrm{b}-\mathrm{n}}\right)$ and $K^{\prime \prime}\left(\mathrm{MPa} \cdot \mathrm{m}^{2-\mathrm{n}}\right)$ are both revised intrusion coefficients.

To evaluate and check the difference between the modified mechanical model and the test curve, we compared the intrusion resistive forces of mechanical feet with variable cross-sectional areas intruding into three kinds of quartz sand, respectively (Figure 14). For both the hemispherical foot and the semicylindrical foot, the difference between the modified mechanical model curve and the test curve was always small before the depth was $35 \mathrm{~mm}$, which means it can even be ignored. Therefore, it can be considered that the modified mechanical model can be used to evaluate the intrusion resistive force of a mechanical foot with a variable cross-sectional area. 


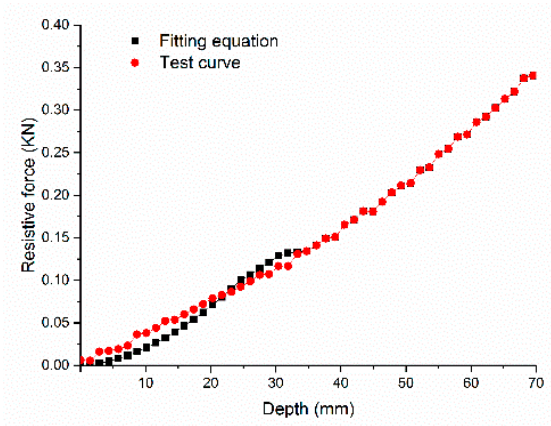

(a) Hemispherical foot on quartz sand 1

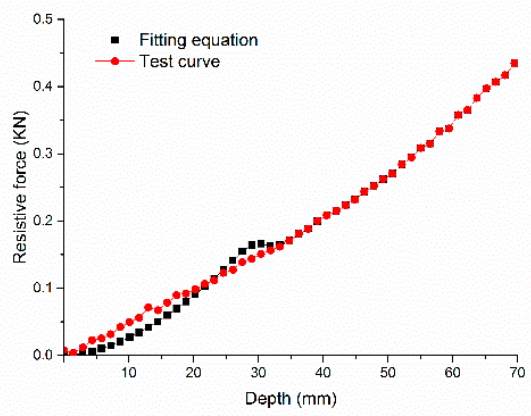

(c) Hemispherical foot on quartz sand 2

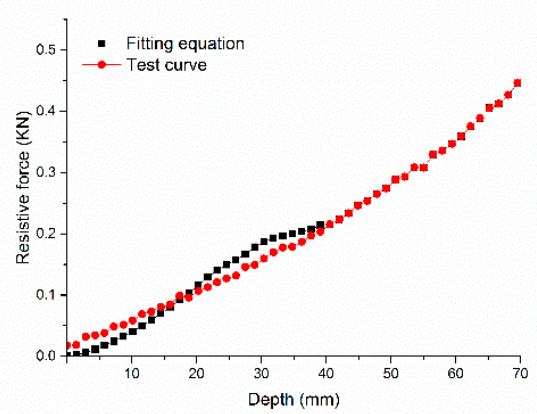

(e) Hemispherical foot on quartz sand 3

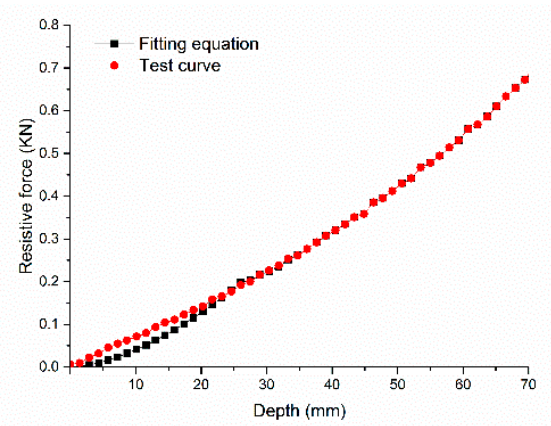

(b) Semicylindrical foot on quartz sand 1

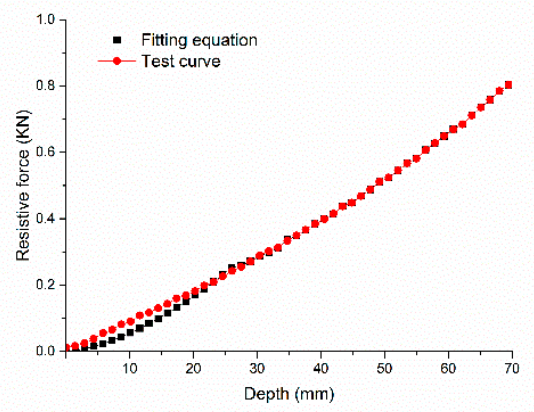

(d) Semicylindrical foot on quartz sand 2

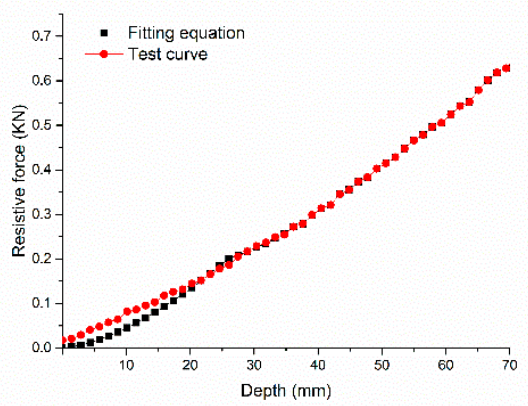

(f) Semicylindrical foot on quartz sand 3

Figure 14. Modified mechanical model evaluation.

\section{Conclusions}

1. Granular media with smaller particle sizes have a higher bulk density and lower angle of stability, but no obvious rule is found for particle shapes of quartz sand with different sizes.

2. The intrusion resistive force and pressure of the hemispherical foot are both less than those of the other three mechanical feet on all three kinds of quartz sand.

3. The intrusion resistive forces of mechanical feet first increase and then decrease with the increasing particle sizes of quartz sand. The resistive force of intruding into spherical particles is less compared with irregular particles. The corresponding resistive forces of mechanical feet are characterized based on the compactness of quartz sand.

4. Based on the intrusion test data, the classic pressure-sinkage model was modified, and a suitable relationship between the intrusion resistive force and the depth of mechanical feet was obtained.

Author Contributions: Data curation, H.Z. and Z.H.; Formal analysis, D.H.; Funding acquisition, R.Z.; Investigation, D.H.; Project administration, R.Z.; Software, D.H.; Supervision, J.L.; Validation, H.Z. and Z.H.; 
Visualization, J.L.; Writing—original draft, D.H.; Writing—review and editing, R.Z. All authors have read and agreed to the published version of the manuscript.

Funding: This work was supported by the National Natural Science Foundation of China (No. 51675221), the Science and Technology Development Planning Project of Jilin Province of China (No. 20180101077JC), the Science and Technology Research Project in the 13th Five-Year Period of Education Department of Jilin Province (No. JJKH20190134KJ), and the Graduate Innovation Fund of Jilin University (No. 101832018C006).

Conflicts of Interest: The authors declare no conflicts of interest.

\section{References}

1. Jaeger, H.M.; Nagel, S.R. Dynamics of granular material. Am. Sci. 1997, 85, 540-545.

2. Hosoi, A.E.; Goldman, D.I. Beneath our feet: Strategies for locomotion in granular media. Annu. Rev. Fluid Mech. 2015, 47, 431-453. [CrossRef]

3. Mehta, A.; Barker, G.C. The dynamics of sand. Rep. Prog. Phys. 1994, 57, 383-416. [CrossRef]

4. Mazouchova, N.; Gravish, N.; Savu, A.; Goldman, D.I. Utilization of granular solidification during terrestrial locomotion of hatchling sea turtles. Biol. Lett. 2010, 6, 398-401. [CrossRef] [PubMed]

5. Li, C.; Zhang, T.; Goldman, D.I. A terradynamics of legged locomotion on granular media. Science 2013, 339, 1408-1412. [CrossRef]

6. Albert, I.; Tegzes, P.; Kahng, B.; Albert, R.; Sample, J.G.; Pfeifer, M.; Barabasi, A.; Vicsek, T.; Schiffer, P. Jamming and fluctuations in granular drag. Phys. Rev. Lett. 2000, 84, 5122-5125. [CrossRef]

7. Albert, I.; Sample, J.G.; Morss, A.J.; Rajagopalan, S.; Barabási, A.L.; Schiffer, P. Granular drag on a discrete object: Shape effects on jamming. Phys. Rev. E 2001, 64, 061303. [CrossRef]

8. Qian, F.; Goldman, D.I. Anticipatory control using substrate manipulation enables trajectory control of legged locomotion on heterogeneous granular media. Proc. SPIE 2015, 9467, 94671U-1.

9. Bergmann, P.J.; Pettinelli, K.J.; Crockett, M.E.; Schaper, E.G. It's just sand between the toes: How particle size and shape variation affect running performance and kinematics in a generalist lizard. J. Exp. Biol. 2017, 220, 3706-3716. [CrossRef]

10. Ding, L.; Gao, H.; Deng, Z.; Song, J.; Liu, Y.; Liu, G.; Iagnemma, K. Foot-terrain interaction mechanics for legged robots: Modeling and experimental validation. Int. J. Robot Res. 2013, 32, 1585-1606. [CrossRef]

11. Sakagami, Y.; Watanabe, R.; Aoyama, C.; Matsunaga, S.; Fujimura, K. The intelligent ASIMO: System Overview and Integration. In Proceedings of the IEEE International Conference on Intelligent Robots and Systems, Lausanne, Switzerland, 30 September-4 October 2002; IEEE: Piscataway, NJ, USA, 2002; pp. 2478-2483.

12. Nelson, G.; Saunders, A.; Neville, N.; Swilling, B.; Bondaryk, J.; Billings, D.; Lee, C.; Playter, R.; Raibert, M. PETMAN: A Humanoid Robot for Testing Chemical Protective Clothing. J. Robot. Soc. Jpn. 2012, 30, 372-377. [CrossRef]

13. Raibert, M.; Blankespoor, K.; Nelson, G.; Playter, R. Bigdog, the rough-terrain quadruped robot. IFAC Proc. Vol. 2008, 41, 10822-10825. [CrossRef]

14. Michael, K. Meet Boston Dynamics' LS3-the Latest Robotic War Machine. Available online: https://ro.uow.edu.au/cgi/viewcontent.cgi?referer=https://scholar.google.com/\&httpsredir=1\& article $=3782 \&$ context $=$ eispapers (accessed on 1 March 2020).

15. Neuhaus, P.D.; Pratt, J.E.; Johnson, M.J. Comprehensive summary of the Institute for Human and Machine Cognition's experience with LittleDog. Int. J. Robot. Res. 2011, 30, 216-235. [CrossRef]

16. Gorner, M.; Wimbock, T.; Hirzinger, G. The DLR Crawler: Evaluation of gaits and control of an actively compliant six-legged walking robot. Ind. Robot 2009, 36, 344-351. [CrossRef]

17. Krotkov, E.; Bares, J.; Kanade, T.; Mitchell, T.; Simmons, R.; Whittaker, R. Ambler: A Six-Legged Planetary Rover. In Proceedings of the Fifth International Conference on Advanced Robotics and Robots in Unstructured Environments, Pisa, Italy, 19-22 June 1991; IEEE: Piscataway, NJ, USA, 1991; pp. 717-722.

18. Wettergreen, D.; Pangels, H.; Bares, J. Behavior-Based Gait Execution for the Dante II Walking Robot. In Proceedings of the IEEE International Conference on Intelligent Robots and Systems and Human Robot Interaction and Cooperative Robots, Pittsburgh, PA, USA, 5-9 August 1995; IEEE: Piscataway, NJ, USA, 1995; pp. 274-279. 
19. Gilardi, G.; Sharf, I. Literature survey of contact dynamics modelling. Mech. Mach. Theory 2002, 37, 1213-1239. [CrossRef]

20. Zhang, T.; Goldman, D.I. The effectiveness of resistive force theory in granular locomotion. Phys. Fluids 2014, 26, 2767-2780. [CrossRef]

21. Li, C.; Umbanhowar, P.B.; Komsuoglu, H.; Koditschek, D.E.; Goldman, D.I. Sensitive dependence of the motion of a legged robot on granular media. Proc. Natl. Acad. Sci. USA 2009, 106, 3029-3034. [CrossRef]

22. Qian, F.; Zhang, T.; Korff, W.; Umbanhowar, P.B.; Full, R.J.; Goldman, D.I. Principles of appendage design in robots and animals determining terradynamic performance on flowable ground. Bioinspir. Biomim. 2015, 10, 056014. [CrossRef]

23. Ding, L.; Deng, Z.; Gao, H.; Nagatani, K.; Yoshida, K. Planetary rovers' wheel-soil interaction mechanics: New challenges and applications for wheeled mobile robots. Intel. Serv. Robot. 2011, 4, 17-38. [CrossRef]

24. Bekker, M.G. Introduction to Terrain-Vehicle Systems; The University of Michigan Press: Ann Arbor, MI, USA, 1969.

25. Wong, J.Y.; Reece, A.R. Prediction of rigid wheel performance based on the analysis of soil-wheel stresses part I-performance of driven rigid wheels. J. Terramech. 1967, 4, 81-98. [CrossRef]

26. Janosi, Z.; Hanamoto, B. Analytical Determination of Drawbar Pull as a Function of Slip for Tracked Vehicle in Deformable Soils. In Proceedings of the 1st International Conference of ISTVES, Turin, Italy, 1 June 1961; International Society for Terrain-Vehicle Systems: Ferrara, Italy, 1961; pp. 707-726.

27. Kang, W.; Feng, Y.; Liu, C.; Blumenfeld, R. Archimedes' law explains penetration of solids into granular media. Nat. Commun. 2018, 9, 1101. [CrossRef] [PubMed]

28. Yeomans, B.; Saaj, C.M. Towards terrain interaction prediction for bioinspired planetary exploration rovers. Bioinspir. Biomim. 2014, 9, 016009. [CrossRef] [PubMed]

29. Bucolo, M.; Buscarino, A.; Famoso, C.; Fortuna, L.; Frasca, M. Control of imperfect dynamical systems. Nonlinear Dynam. 2019, 98, 2989-2999. [CrossRef]

30. Gravish, N.; Goldman, D.I. Effect of volume fraction on granular avalanche dynamics. Phys. Rev. E 2014, 90, 032202. [CrossRef]

31. Brzinski, T.A.; Mayor, P.; Durian, D.J. Depth-dependent resistance of granular media to vertical penetration. Phys. Rev. Lett. 2013, 111, 168002. [CrossRef]

32. Stone, M.B.; Barry, R.; Bernstein, D.P.; Pelc, M.D.; Tsui, Y.K.; Schiffer, P. Local jamming via penetration of a granular medium. Phys. Rev. E 2004, 70, 041301. [CrossRef]

33. Zhang, R.; Han, D.L.; Ji, Q.L.; He, Y.; Li, J.Q. Calibration methods of sandy soil parameters in simulation of discrete element method. Trans. Chin. Soc. Agric. Mach. 2017, 48, 54-61.

34. Shi, L.R.; Wu, J.M.; Zhao, W.Y.; Sun, W.; Zhang, F.W.; Sun, B.G. Establishment and parameter verification of farmland soil model in uniaxial compression based on discrete element method. J. China Agric. Univ. 2015, 20, 174-182.

35. Zhang, R.; Han, D.L.; He, Y.; Wan, H.J.; Ma, S.S.; Li, J.Q. Drag reduction and wear resistance mechanisms of a bionic shovel by discrete element method simulation. Simul. Soc. Mod. Sim. 2019, 95, 231-239. [CrossRef]

36. Aguilar, J.; Goldman, D.I. Robophysical study of jumping dynamics on granular media. Nat. Phys. 2016, 12, 278-283. [CrossRef]

(C) 2020 by the authors. Licensee MDPI, Basel, Switzerland. This article is an open access article distributed under the terms and conditions of the Creative Commons Attribution (CC BY) license (http://creativecommons.org/licenses/by/4.0/). 